\title{
Dorsal midline fate in Drosophila embryos requires twisted gastrulation, a gene encoding a secreted protein related to human connective tissue growth factor
}

\author{
Elizabeth D. Mason, Kenneth D. Konrad, ${ }^{1}$ Chris D. Webb, and J. Lawrence Marsh ${ }^{2}$ \\ Developmental Biology Center and the Department of Developmental and Cell Biology, University of California, Irvine \\ California 92717 USA
}

The twisted gastrulation (tsg) gene is one of seven known zygotic genes that specify the fate of dorsal cells in Drosophila embryos. Mutations in these genes cause at least some of the cells on the dorsal half of the embryo to adopt more ventral cell fates leading to the proposal that most of these genes participate in establishing, maintaining, or modulating a gradient of a single signaling molecule DECAPENTAPLEGIC (DPP). We have examined the effects of tsg mutations on the development of cuticule elements, expression of a region specific enhancer trap, and patterns of mitotic domains. Mutations of tsg only affect the fate of a narrow strip of dorsal midline cells and do not affect dorsal ectoderm cells. However, the pattern of $t s g$ expression is not coincident with the territories affected by $t s g$ mutations. Structural analysis of the $t s g$ gene reveals features of a secreted protein suggesting an extracellular site of action. The TSG protein bears a weak resemblance to human connective tissue growth factor (CTGF), a TGF- $\beta$-induced protein. We propose that dorsal midline cell fate is specified by the combination of both a TSG and a DPP signal to which the dorsal midline cells are uniquely competent to respond.

[Key Words: twisted gastrulation; connective tissue growth factor (CTGF) Drosophila; decapentaplegic (DPP)]

Received April 8, 1994; revised version accepted May 18, 1994.

To date, the zygotic dorsal patterning genes studied are expressed in overlapping dorsoventral $(\mathrm{D} / \mathrm{V})$ domains rather than spatially discrete domains like the GAP genes (Rushlow and Arora 1990; Ferguson and Anderson 1991; St. Johnston and Nüsslein-Volhard 1992). Mutations in these genes (termed ventralizing genes) also affect overlapping territories (i.e., even weak mutations of the zygotic ventralizing genes affect dorsal midline structures, whereas more severe alleles affect the more lateral dorsal ectoderm structures to varying degrees). The known zygotic $\mathrm{D} / \mathrm{V}$ patterning genes include the decapentaplegic (dpp), tolloid (tld), screw (scw), shrew (srw), zerknüllt (zen), short gastrulation (sog), and twisted gastrulation (tsg) genes (Jurgens et al. 1984; Nüsslein-Volhard et al. 1984; Wakimoto et al. 1984; Wieschaus et al. 1984; Zusman and Wieschaus 1985; Irish and Gelbart 1987) (sog is unusual in being required in the

\footnotetext{
${ }^{1}$ Present address: Advanced Technology Center, Beckman Instruments, Inc., Fullerton, California 92634 USA.

${ }^{2}$ Corresponding author.
}

ventral part of the embryo for dorsal patterning and will not be considered further here).

The only gene required for development of all dorsal structures is the dpp gene (Irish and Gelbart 1987). All other ventralizing mutants affect the dorsal midline and then increasingly larger dorsolateral domains as more severe alleles are examined (this study; Arora and Nüsslein-Volhard 1992). These observations have prompted the suggestion that a gradient of DPP activity may provide the primary patterning signal in the dorsal half of the embryo with some or all of the other ventralizing genes serving to modulate or maintain that gradient (Shimell et al. 1991; Arora and Nüsslein-Volhard 1992; Ferguson and Anderson 1992b). The DPP and TLD proteins are related most closely to bone morphogenetic protein $(\mathrm{BMP} \mid-2 / 4$, two transforming growth factor- $\beta$ (TGF- $\beta$ ) family members (Padgett et al. 1993), and BMP1, a metalloprotease that copurifies with BMP-2/Shimell et al. 1991) and is thought to participate in activating the latent form of these BMPs (Wang et al. 1988; Wozney et al. 1988; Celeste et al. 1990). Thus, TLD may modulate 
DPP activity biochemically. Alleles of tld that exacerbate the effect of some $d p p$ alleles provide genetic support for this view (Ferguson and Anderson 1992b). Similarly, certain alleles of $s c w$ (recently identified as also related to BMPs of the TGF- $\beta$ class; K. Arora, pers. comm.) also show antagonistic interactions with $d p p$ alleles (V. Twombly and W.M. Gelbart, pers. comm.). On the basis of the suppression of alleles of $t l d$, srw, and scw by extra doses of $d p p$, these genes have been placed upstream of $d p p$ as putative effectors of DPP activity (Ferguson and Anderson 1992b). In contrast, the failure of extra copies of $d p p$ to suppress tsg and zen mutations suggests that these two genes may act downstream of or in parallel with DPP (Ferguson and Anderson 1992b). It has been shown that the presence of DPP is necessary to sustain zen transcription (Ray et al. 1991) and is sufficient to induce zen transcription, therefore suggesting that ZEN, a transcription factor, functions downstream of DPP to effect only the dorsal-most cell fates (Ferguson and Anderson 1992a). Thus, TLD, SCW, and SRW are postulated to modulate DPP activity resulting in zen expression and proper dorsal patterning, whereas the role of tsg is unknown.

We have analyzed the developmental effects of $t s g$ mutants and the structure of the tsg gene. We find that $t s g$ mutations affect only the dorsal midline cells, and in contrast to mutations of $d p p$ or the putative effector genes $t l d$ and $s c w$, tsg mutations do not affect the lateral dorsal ectoderm. We find that the TSG protein shares some structural features with a new human growth factor, connective tissue growth factor (CTGF) (Bradham et al. 1991). The TSG protein appears to be secreted. The restricted effect of $t s g$ mutations in contrast to those of $d p p$, tld, and scw and the structural features of a secreted protein suggest an alternative to the single morphogen (DPP) gradient model (Ferguson and Anderson 1992a), namely that TSG represents a second class of peptide growth factor that may be part of a combinatorial signaling mechanism that specifies dorsal patterning in Drosophila.

\section{Results}

tsg mutations affect cell fate in the dorsal midline cells but not in dorsal ectoderm

Mutations of $d p p$ or its putative effectors, tld and scw, lead to loss of dorsal ectoderm, loss of dorsal midline structures, or both, with an accompanying expansion of ventral fates depending on the severity of the mutant (Arora and Nüsslein-Volhard 1992; Ferguson and Anderson 1992a; Wharton et al. 1993). If TSG affects an overall gradient of DPP activity (see Fig. 10A, below), then tsg mutations should affect both dorsal midline and dorsal ectoderm cell fates as seen with tld and scw null mutations. By three criteria, we find that $t s g$ mutations affect only dorsal midline cells with no accompanying expansion of the more ventrolateral regions. To illustrate, $t s g$ mutant embryos are compared below with embryos homozygous for a tld null mutation.
We examined the effect of $t s g$ mutations on the development of cuticle structures by first asking whether the ventral denticle belts are expanded in tsg mutant embryos as they are in embryos mutant for $d p p$ or its effectors. Comparing tsg mutant embryos and their normal siblings, the number of denticles in row one of abdominal segment A5 were 28.1 \pm 2.5 and 27.6 \pm 2.1 , respectively, and in row one of A6 they were $29.6 \pm 2$ and $29.5 \pm 1.6$, respectively ( $n=18$ for each). The numbers are not significantly different when subjected to Fischer's exact test, $\mathrm{P}=0.57$, indicating no expansion of denticle belts with either $t s g$ allele. The lack of denticle expansion in tsg mutants compared with $t l d$ and wild type can be seen in Figure 1A-C.

We then examined tsg mutant embryos for cuticle elements in the larval head and tail that derive from both the dorsal midline cells and the more lateral dorsal ectoderm cells. All tsg mutant cuticles examined $(n=20$; Fig. 2) lacked the following midline-derived structures: labrum, labral sense organ, dorsal bridge and dorsal arm of the pharyngeal skeleton, and posterior tuft (Jürgens et al. 1986; Jürgens 1987). On the other hand, structures that arise from the immediately adjacent dorsal ectoderm anlagen of the head were not deleted in $t s g$ : vertical plates and ventral arm of the pharyngeal skeleton, cirri, and maxillary and antennal sense organs, and in the tail the filzkörper and anal sense organs. In contrast, in tld mutant embryos as well as $d p p$ and $s c w$, both dorsal midline and adjacent dorsal ectoderm structures are affected (Arora and Nüsslein-Volhard 1992; Ferguson and Anderson 1992b). The presence of lateral elements in tsg mutant embryos and their absence in tld embryos illustrates the restricted domain affected by $t s g$ mutations.

In the second set of experiments, we compared the expression pattern of a dorsal ectoderm-specific enhancer trap line in wild type, $t s g$, and $t l d$ mutants. The enhancer trap is expressed in paired stripes in the dorsal ectoderm (Fig. 3A) during the germ band extension stage with no expression in the amnioserosa cells (i.e., across the dorsal midline). In ventralizing mutant embryos, the advancing germ band plunges under the dorsal blastoderm cells leaving the cells that normally form the amnioserosa exposed dorsally. In $t s g$ mutant embryos, the enhancer trap is expressed in unbroken dorsal stripes whose ventral boundary is unchanged compared with wild type (Fig. 3B). In contrast, the ventral boundary of the enhancer trap expression is shifted dorsally in tld mutants (Fig. 3C) and in $d p p$ and scw mutants (not shown).

In the third series of experiments, we examined mitotic domains as early indicators of cell identity. After 13 synchronous divisions, the cells of the gastrula undergo a series of asynchronous divisions characteristic of different spatial domains of the embryo (Foe 1989). In $t s g$ mutant embryos, the dorsal-most cells along the entire anteroposterior $(\mathrm{A} / \mathrm{P})$ axis adopt the mitotic schedules of their immediately lateral neighbors. In particular, the dorsal midline cells in the head divide with domains 1,5 , and 6 so that these domains are no longer interrupted by domains 18 and A but extend across the midline (Fig. 4). 


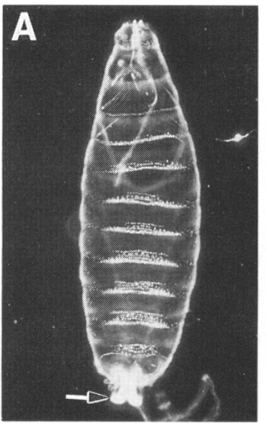

wt

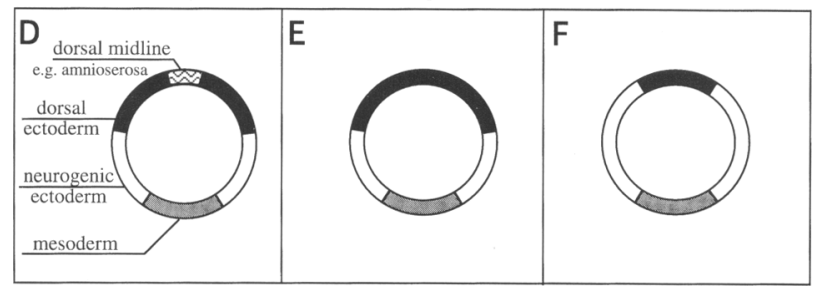

Figure 1. The dorsal/ventral fate map is not shifted in $t s g \mathrm{mu}-$ tants as it is in tld. $(A-C)$ Cuticles of wild-type $(A), t s g(B)$, and tld $|C\rangle$ mutant embryos. Cuticles are positioned to reveal their ventral aspect; anterior is up. The anterior of the tsg and tld embryos is abnormally extended because of failure of head involution. In the posterior, the dorsolaterally derived filzkörpers (arrow) are fully developed but internal in tsg mutants; in tld mutants they are either partially formed or absent. In $t s g(B)$, there is no expansion of denticle bands as seen in tld $(C), d p p$, and $s c w$ (not shown), suggesting that the neurogenic ectoderm does not expand in tsg mutants as it does in mutants of $d p p$, tld, and $s c w .(D-F)$ Cross section of the fate map of wild-type, tsg and tld embryos at the blastoderm stage near the midpoint of the embryo (i.e., the segmented portion). The embryo is $\sim 72$ cells in circumference and divided into four regions: the dorsalmost amnioserosa (5-6 cells), the dorsal ectoderm $(\sim 10$ cells), the neurogenic ectoderm $(\sim 13$ cells $)$, and the mesoderm $\mid \sim 15-$ 16 cells). In null mutants of $t s g$, the ventrolateral extent of the dorsal ectoderm remains unchanged, whereas the dorsal-most cells, which would normally form the amnioserosa or other midline structures, develop as dorsal ectoderm or dorsolateral structures. In contrast, null mutants of $t l d$ and $s c w$ cause the entire fate map to be shifted dorsally with an actual decrease of cells fated to be dorsal ectoderm and an accompanying expansion of the ventrolateral regions. In the extreme, the null mutant of $d p p$ has no dorsal ectoderm and denticle bands encircle the entire cuticle (not shown). At this point along the A/P axis the dorsal midline cells give rise to the amnioserosa; in the head and tail region other dorsal midline structures are formed (described in legend to Fig. 2). The ventral mesoderm invaginates and does not form external structures; therefore, the denticles that arise from the neurogenic ectoderm are ventrolateral markers. Photographs were made using a $10 \times$ dark-field objective.

Domain 7 comprises a group of mitotic cells found inside the lateral folds of the cephalic furrow. In tsg mutants, dorsal midline cells divide with domain 7 causing the furrow to extend across the midline. During late cell cycle 14 (not shown here), the dorsal-most cells of domain $\mathrm{A}$, which would normally halt division and form amnioserosa, instead divide with the immediately dorsolateral domain 19 cells. In embyros mutant for the other ventralizing genes, even in the weakest mutants (i.e., zen and srw), some or all of the dorsolateral domains shift dorsally, whereas the ventral mitotic domains expand into the lateral regions /see Fig. 9 in Arora and Nüsslein-Volhard 1992). We do not see dorsal shifts of mitotic domains in tsg mutant embryos. Thus, by the three criteria described, the identity of the lateral dorsal ectoderm cells is not changed by tsg mutations, whereas dorsal-midline cells along the entire anteroposterior axis adopt the identity of their immediately lateral neighbors.

\section{Identification and expression of the tsg gene}

Genomic clones spanning the tsg region were first identified by Goralski \{1985). We isolated embryonic cDNA clones using a genomic DNA fragment that hybridizes to the only transcript in the region present at gastrulation. We identified this transcript as tsg by rescuing tsg mutations with a P-element construct containing a 1.4-kb DNA fragment that extends $33 \mathrm{bp} 3^{\prime}$ and $480 \mathrm{bp} 5^{\prime}$ of the transcribed region (E.D. Mason and J.L. Marsh, unpubl.). The pattern of $t s g$ expression was determined by hybridizing developmental Northern blots with strand-specific probes from the cDNA (Fig. 5). A single 1.0-kb transcript was detected in the 1.5- to 3.0-hr embryo collection only with no hybridization detected at other stages despite overexposure of the autoradiographs. The sense strand control failed to hybridize to any transcripts (not shown).

Whole mount in situ hybridization revealed several notable features of $t s g$ expression (Fig. 6). First, tsg expression is restricted to the dorsal $40-50 \%$ of the egg circumference throughout its period of expression, thus following the dorsal on/ventral off pattern of the other dorsal group genes, $d p p$, tld, and zen. This pattern is thought to be set by DORSAL through repression in ventral cells (Doyle et al. 1986; St. Johnston and Gelbart 1987; Shimell et al. 1991) and tsg is expressed circumferentially in embryos from dorsal mutant females $(C$. Webb and J.L. Marsh, unpubl.). However, the initial appearance of $t s g$ is not uniform across the dorsal half of the embryo as it is in dpp, tld, and zen (Doyle et al. 1989; Ray et al. 1991; Shimell et al. 1991). Hybridization to tsg mRNA is first detected at nuclear cycle 13 in the syncytial embryo- $\sim 1 \mathrm{hr}$ and $45 \mathrm{~min}$ of development /Campos-Ortega and Hartenstein 1985) when it appears in two domains, a broad mid-dorsal saddle and an anterior cap (Fig. 6A), both of which are continuous across the dorsal midline (Fig. 6B). During cellularization, transcripts disappear from the dorsal midline in both the anterior and middle domains to give a bilaterally symmetrical pattern and the initial mid-dorsal domain refines into a series of four diffuse stripes along the $\mathrm{A} / \mathrm{P}$ axis (Fig. $6 \mathrm{C}$ ). As the germ band extends during stage $7(\sim 10 \mathrm{~min})$ and stage 8 ( $30 \mathrm{~min}$ ) (Campos-Ortega and Hartenstein 1985), the anterior patches of $t s g$ expression fade and the mid-dorsal stripes are located between the anterior transverse furrow $(\mathrm{ATF})$ and the posterior transverse furrow $(\mathrm{PTF})$ (Fig. 6D). As the PTF deepens, the tsg-expressing cells become incorporated into the PTF (Fig. 6E). The tsg mRNA persists as the PTF and the proctodeal fold, 
Figure 2. tsg lacks only dorsal midline-derived cuticular structures; in $t$ ld, dorsolaterally derived structures are absent too. $(A)$ Head region of a wild-type cuticle showing the dorsal midline and dorsolaterally derived head structures. Dorsal midline-derived structures of the larval head include the labrum (AKA the median tooth) (l), the dorsal bridge $(\mathrm{db})$, and the dorsal arm (da). Structures arising from the dorsal ectoderm (see Fig. 1D) (listed from the most dorsally derived) include the maxillary sense organs (ms), antennal sense organs (as), vertical plate (vp), and, still more laterally, the ventral arms (va), lateralgerate (lg), and the mouth hooks (mh) (Jürgens et al. 1986). Mouth hooks in this preparation are visible in a different focal plane shown in the inset. $(B)$ Head region of a tsg mutant cuticle. The head fails to involute in the ventralizing mutants and, thus, is seen as inside out. All of the dorsolaterally derived structures are still present; only the labrum, dorsal bridge, and dorsal arm, derived from dorsal midline cells are absent. The two insets, at different focal planes, show a mouth hook and antennal sense organ whose locations are denoted by broken lines in the main photo. $(C)$ Head region of tld mutant cuticle. All dorsal and dorsolaterally derived structures are absent except the most ventral mouth hooks and occasionally the antennal sense organs (not present here). (Inset) The mouth hooks not in focus in the main photo.
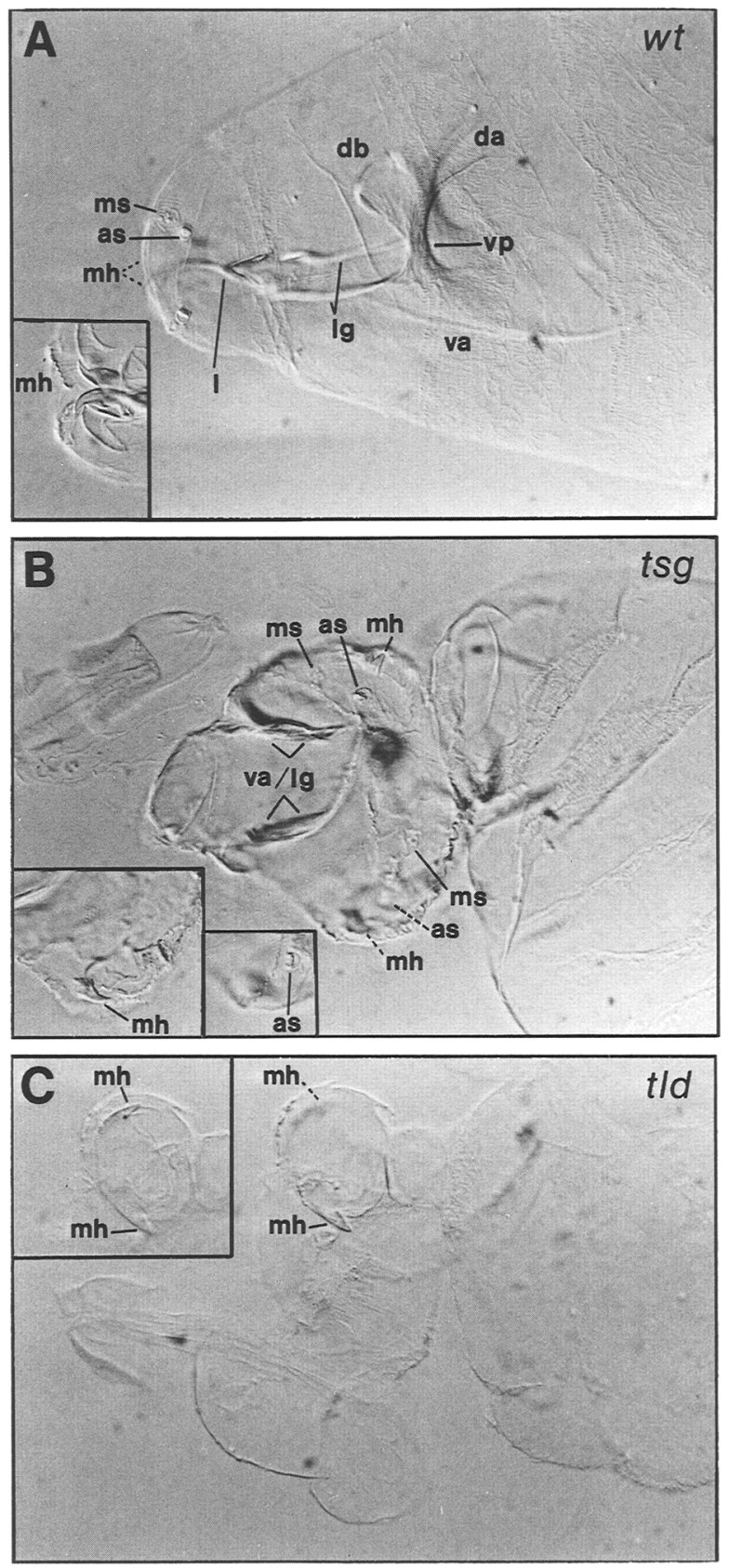

which forms the pouch for pole cells, fuse, and become onefold (Campos-Ortega and Hartenstein 1985) (Fig. 6F). By the time that the stomodeal invagination begins $(\sim 4$ $\mathrm{hr}$ and $20 \mathrm{~min}$ ), tsg mRNA is not detectable. Thus, both Northern blots and in situ hybridization of individual embryos indicate that $t s g$ expression is restricted to the period of gastrulation.

To position the mid-dorsal stripes of $t s g$ accurately on the fate map, we hybridized wild-type embryos with both a tsg probe and a fushi tarazu (ftz) probe. The $f t z$ gene is expressed in seven stripes corresponding to parasegments 2-14 (Hafen et al. 1984). The double staining shown in Figure 7 demonstrates that the domain of $t s g$ expression is located between parasegments 4 and 10 (i.e., $f t z$ stripes 2 and 5). We find that a 1:1000 dilution of $f t z$ probe gives a signal intensity similar to the intensity of $t s g$-positive cells whose staining has not yet become punctate (see below). Because the probes were of similar specific activity and the complexity of the $f t z$ probe is 1.7 $\mathrm{kb}$ versus 563 nucleotides for $t s g$, we conclude that the ts $g$ mRNA is $<1 \%$ as abundant as $f t z$ mRNA.

The localization of $t s g$ transcripts within the cells also changes during development. During the last cleavage divisions, tsg transcripts are localized uniformly around the apical side of the nucleus much like $f t z$ transcripts. During cellularization, the transcripts in some cells be- 


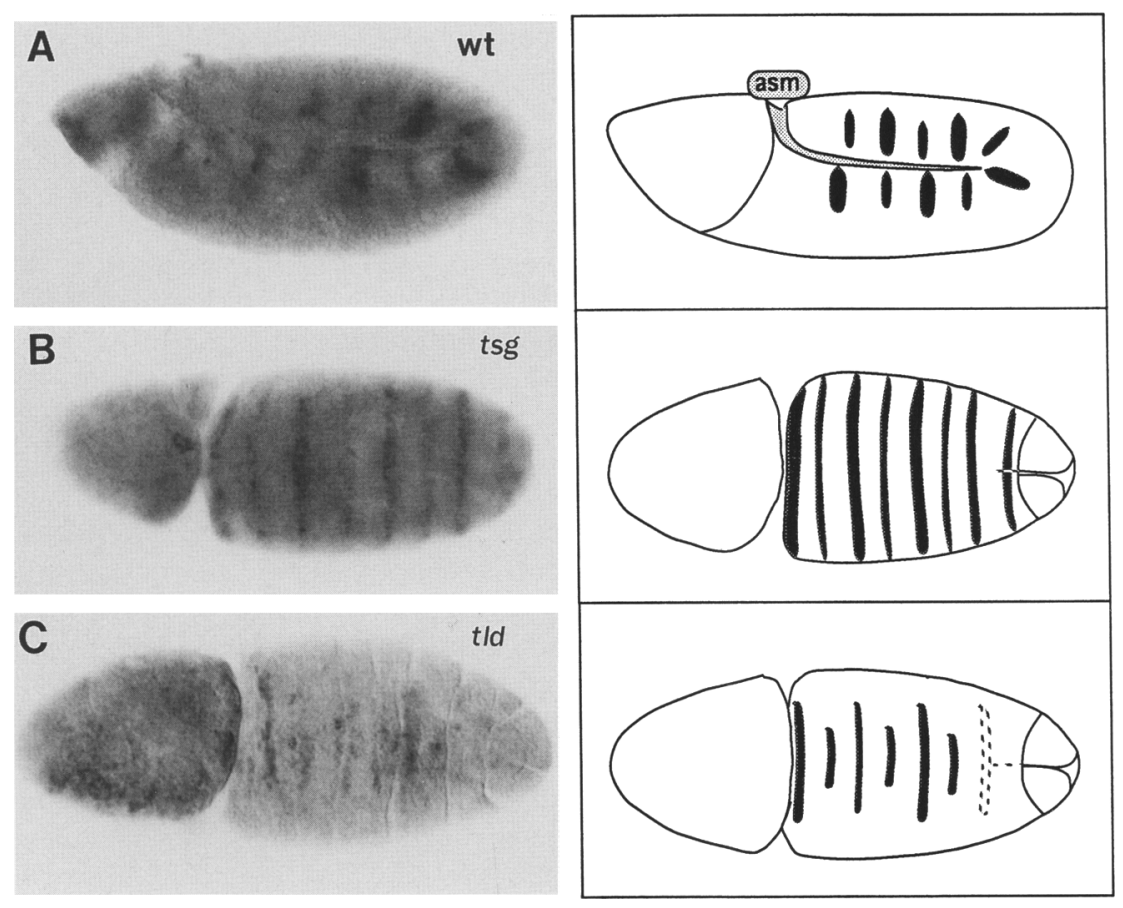

Figure 3. Expression of a dorsal ectoderm marker in wild type, tsg, and tld. The P62 LacZ enhancer trap marker stains the dorsal ectoderm in a series of $A / P$ stripes at germ-band extension. $(A)$ Lateral view of wild type containing the P62 marker at germ-band extension. The germ band extends over the dorsal-most cells, the amnioserosa (ASM), which move laterally to accommodate this extension. The amnioserosa becomes sandwiched between the dorsal ectoderm (see cartoon illustration of wild type, right). Note how the amnioserosa is devoid of stain. (B) Dorsal view of a tsg mutant embryo at germ-band extension and accompanying cartoon illustration (right). The germ band does not extend around the embryo but, instead, plunges internally; therefore, the dorsal-most cells do not become sandwiched but can be seen in a dorsal view of the embryo. Note how the ectodermal marker stains $t s g$ in stripes that extend across the entire dorsal $40 \%$ of the embryo. Cells normally fated to be dorsal ectoderm retain dorsal ectoderm fate in tsg mutants. In addition, cells in the midline region, where amnioserosa would normally form, also express the P62 ectodermal marker, indicating that these midline cells have been refated as dorsal ectoderm. $(C)$ Dorsal view of a $t l d$ mutant embryo at germ-band extension and accompanying cartoon illustration (right). As in $t s g$, the germ band in $t l d$ plunges internally and the dorsal midline cells, where amnioserosa would normally be, now stain with the dorsal ectodermal lac $Z$ marker, but in contrast to $t s g$ mutants where the stain extends across the entire dorsal $40 \%$ of the embryo, the stain is substantially narrowed in width indicating a fate map shift where the dorsal ectodermal region has shifted dorsally.
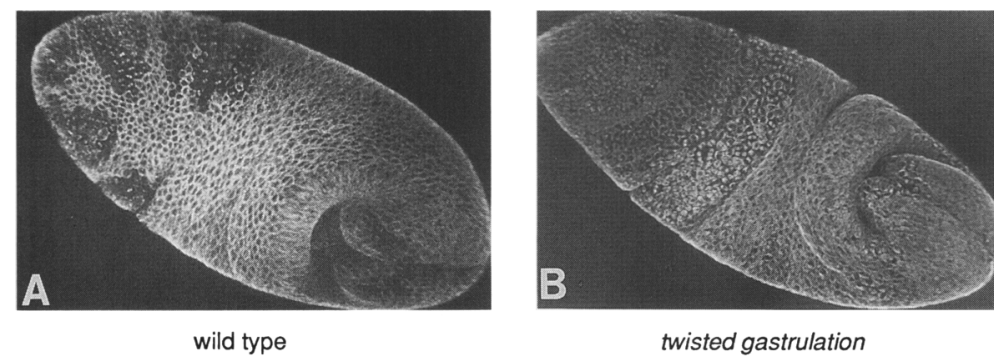

twisted gastrulation

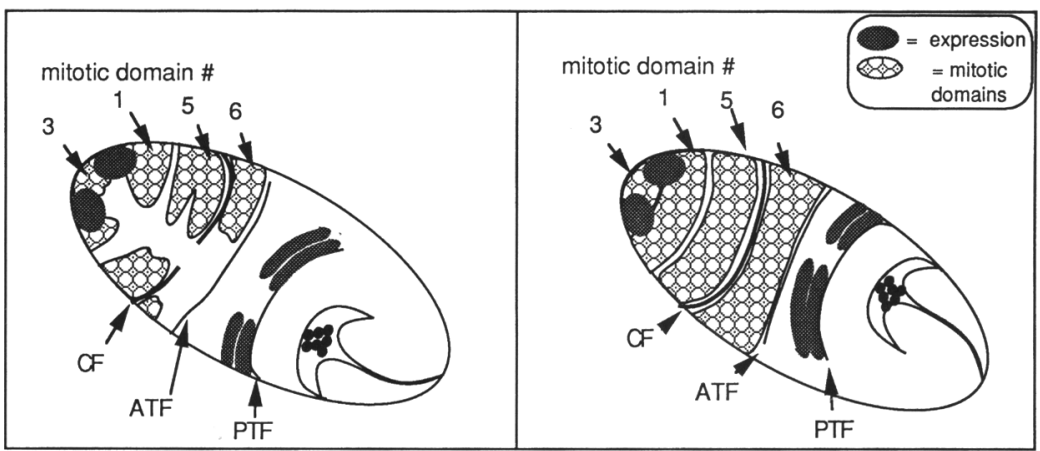

Figure 4. Mitotic domains in tsg and normal embryos. Mitotic domains are altered in $t s g$ mutants. Mitotic domains that are normally bilaterally symmetric are now expanded across the dorsal midline with no shift of their lateral boundaries to a more dorsal position. Three to $6-\mathrm{hr}$ embryos were collected from wild-type and tsg mutants and stained with anti-tubulin antibodies to reveal mitotic figures. In wild-type embryos $(A)$, cells along the dorsal midline between mitotic domains 1,5 , and 6 are never seen dividing at this stage. In tsg mutants (B), dividing cells are seen all across the midline showing that several mitotic domains (e.g., domains 1, 5, and 6) are expanded across this dorsal region. When viewed from the side, it is apparent that the ventral extent of domain 6 remains unchanged; thus, it is not shifted dorsally as with mutations of the potential $d p p$ effectors $s c w$, srw, and tld (Arora and Nüsslein-Volhard 1992) but, instead, has expanded into the dorsal region. A similar expansion of mitotic domain 19 across the midline where amnioserosa cells would normally form also occurs later in cell cycle 14 (not shown). The accompanying cartoon indicates the regions of tsg expression relative to the altered mitotic domains. Only two stripes of $t s g$ expression are shown because at this stage, some of the tsg-expressing cells have invaginated into the posterior transverse furrow (PTF) (see Fig. 6D). The cephalic furrow $(\mathrm{CF}$ ) invaginates across the dorsal midline in the mutant but not in wild type. Note that some of the affected cells are many cell diameters removed from the tsg-expressing cells (e.g., the dorsal-most cells that separate the two regions of mitotic domains 5 and 6 are at least 10 cells removed from the nearest $t$ sg-expressing cells at this stage). (ATF) anterior transverse furrow. 


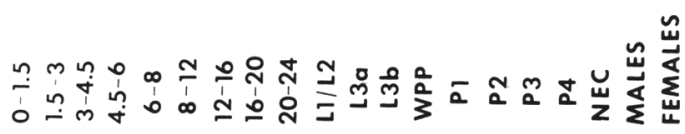

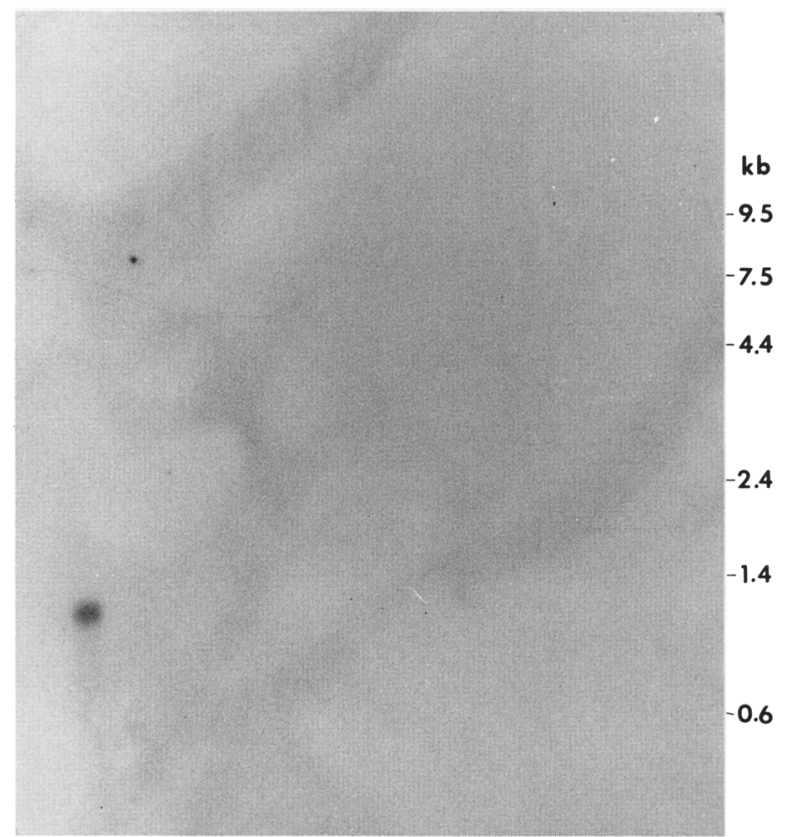

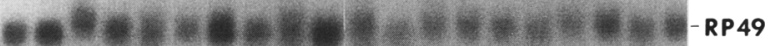

Figure 5. Developmental Northern blot of $t$ sg expression. Embryonic stages are labeled in hours after egg laying at $25^{\circ} \mathrm{C}$. Larval stages were harvested from 4-hr egg collections and allowed to age; (L1/L2) 24-72 hr; (L3a) 72-90 hr; (L3b) 90-108 hr (early and late third-instar larvae, respectively). Pupal stages are white prepupae (WPP) collected by hand; (P1-4) selected as WPP and aged 1, 2,3, and 4 days. Adult stages include newly enclosed (NEC) adults (0-2 hr posteclosion) and males and females. Each lane contains $20 \mu \mathrm{g}$ of total RNA. The blot was probed with a ${ }^{32} \mathrm{P}$-labeled antisense probe from a tsg cDNA clone. (Bottom) Hybridization of the ribosomal protein gene probe RP49 as a control for RNA content.

come concentrated at the apical surface. At the surface of the blastoderm, one can see isolated cells staining very intensely compared with their neighbors and the image of the apical nucleus is obscured unlike neighboring cells with more deeply localized transcripts. Compare the uniform staining of $f t z$ with the punctate staining of $t s g$ in Figure 7B. Apical localization of $t s g$ is also visible in the anterior domain in Figure 6C. This intracellular localization takes place asynchronously in a salt-and-pepper fashion.

\section{Molecular organization of the tsg gene}

Both genomic and cDNA subclones encoding the tsg transcript were completely sequenced in both orientations and found to be colinear indicating that the tsg gene contains no introns (Fig. 8A). The longest cDNA (tsg2) is $980 \mathrm{bp}$ (including a 42-bp poly|A) tail), whereas the mRNA is $\sim 1 \mathrm{~kb}$ and thus, within the limits of resolution of the RNA blots, the cDNA is full length. In addition, a second cDNA (tsg20) begins $2 \mathrm{bp}, 5^{\prime}$ of $t s g 2$, but is truncated at the $3^{\prime}$ end. The genomic sequence contains a putative TATA box -30 nucleotides from the $5^{\prime}$ end of the $t s g 20 \mathrm{cDNA}$ and the first 5 nucleotides of the cDNA (ATCAT) match the first 5 nucleotides of the consensus transcription start sequence ATCA $/ \mathrm{G} / \mathrm{T} \mid \mathrm{T} / \mathrm{C} /$ T) (Hultmark et al. 1986). The cDNA sequence contains a single long open reading frame (ORF) of 780 nucleotides beginning with the first ATG $30 \mathrm{bp}$ downstream of the putative RNA start site. This ORF has been confirmed functionally by translation of expression vector subclones in bacteria and by translation of full-length transcripts in reticulocyte lysates (not shown). The ORF is followed by a 130-nucleotide $3^{\prime}$-untranslated region that has a poly(A) addition sequence, AATAAA, $18 \mathrm{nu}-$ cleotides from the start of the poly(A) tail. On the basis of an appropriately located transcription start signal that matches well with the transcription consensus, the physical size of the polyadenylated transcript compared with the cDNA, and the fact that two cDNAs begin within $2 \mathrm{bp}$ of one another, we conclude that the entire transcription unit is represented in the sequence presented.

\section{TSG appears to be secreted}

Conceptual translation of the $t s g$ mRNA yields an acidic protein of $27.2 \mathrm{kD}$, predicted pI of 3.9 with a high cysteine content $(10 \%)$, and one potential amino-linked glycosylation site conforming to the AsnXSer/Thr consensus. The protein exhibits an amino-terminal stretch of 21 hydrophobic residues resembling a signal sequence and no internal hydrophobic region capable of spanning a membrane, indicating that it is likely secreted. The most likely site for cleavage is after Ala-21 with a cleavage value of 9.2 calculated by the method of von Heinje (1986) using PC Gene. The predicted cleavage would produce a protein of $24.8 \mathrm{kD}$. The protein exhibits a hydrophobic amino terminus and two clusters of cysteines (open arrowheads) in the amino- and carboxy-terminal regions of the protein (Fig. 8B). Thus, TSG exhibits features commonly found in extracellular proteins.

\section{TSG is distantly related to a family} of vertebrate proteins

A homology search of protein data bases was conducted using the experimental GENINFO (R) BLAST Network Service set up by the National Center for Biotechnology Information (Bilofsky and Burks 1988). No extensive similarities were identified; however, the BLAST algorithm (Altschul et al. 1990) identified human CTGF (Bradham et al. 1991) and its mouse homolog, the FISP12 protein (Ryseck et al. 1991), as sharing a limited region of similarity with TSG in the amino-terminal half of the protein. These two proteins belong to a family of structurally related polypeptides that include the prod- 

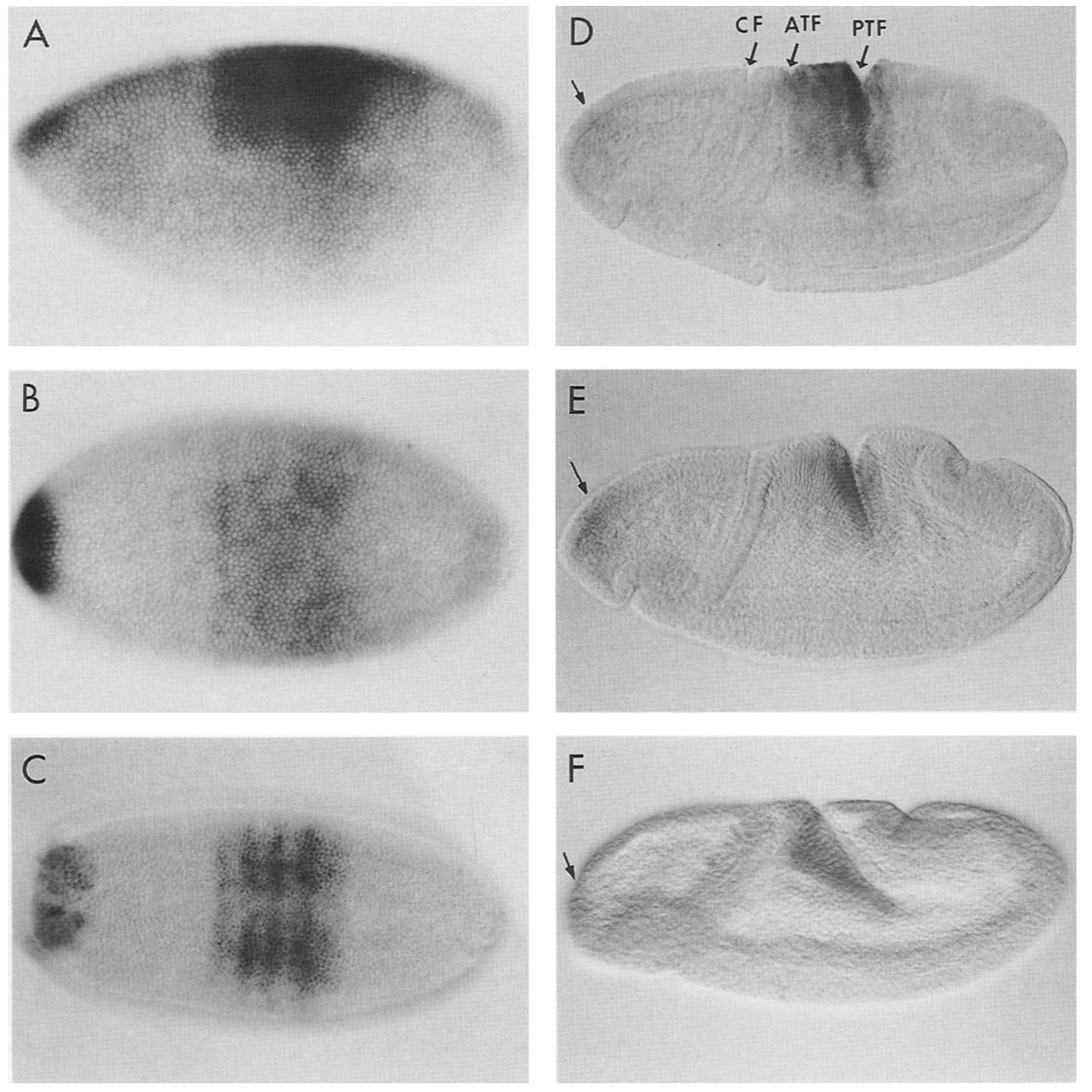

Figure 6. In situ localization of $t s g$ expression. Staged embryos were hybridized with digoxigenin-labeled tsg antisense RNA and stained with alkaline phosphatase. Hybridization with the sense strand gave no signal (not shown). Anterior is to the left in all panels. $(A, B)$ Lateral and dorsal views of mid- and late stage 4 syncytial blastoderm embryos (approximately nuclear division 12-13) showing the initial broad diffuse expression of tsg. $(C)$ Dorsal view of stage 5 cellular blastoderm showing refinement into four graded stripes in the mid-dorsal region and a paired domain in the anterior region. Note lack of expression along the dorsal midline and the nonuniform staining of individual cells. $(D)$ Lateral view of an early stage 7 embryo (early phase of germ band extension) showing the expression domain located between the ATF and PTF. The cephalic furrow $(\mathrm{CF})$ is indicated for reference. Arrow at left in $D, E$, and $F$ indicates fading anterior expression. $(E)$ Late stage 7 showing how the tsg-expressing cells have become incorporated into the deepening PTF and line the anterior side of this fold. $(F)$ tsg-expressing cells are fully incorporated into and line the pouch formed by the PTF. By this time the ATF has fused with the PTF, extensive cell movements and shape changes have occurred, and the amnioserosa has become more distinct. ucts of the CEF-10 gene of chickens (Simmons et al. 1989 ) and the cyr61 gene of mice (O'Brien et al. 1990), as well as the more distantly related group of insulin-like growth factor-binding proteins (IGFBPs) from several mammals (for an overview of the IGFBPs, see Baxter 1988). Two distinguishing features of these proteins are (1) an overall structure exhibiting cysteine-rich aminoand carboxy-terminal domains flanking a cysteine-free nonconserved central core, and $(2)$ a region of similarity surrounding the sequence $\mathrm{C}^{\mathrm{G}} / \mathrm{H} C \mathrm{CXXC}$. This region of TSG is aligned with its four closest relatives, human CTGF, mouse FISP-12, and the somewhat more distantly related growth factor-inducible proteins, CEF-10 and CYR61 in Figure 9. Although the overall identity of aligned amino acids is only $\sim 19 \%, 59 \%$ (i.e., 19 of 32 ) of residues in this region are conserved as are the cysteines here and in other regions of the protein.

\section{Discussion}

Here, we provide evidence to support the hypothesis that the requirement for tsg function is restricted to the dorsal midline cells of the early embryo. We find that the pattern of tsg expression is not concordant with the regions affected by tsg mutations and that the tsg gene encodes a secreted protein. Some of the dorsal midline cells whose behavior is affected in tsg mutant embryos are $\geqslant 10$ cells removed from the tsg-expressing domains seen after cellularization (see Figs. 4 and 6). Three interpretations are possible: (1) The protein itself may act at a distance to signal these cells; (2) the cells expressing tsg at gastrulation may initiate a signal that is relayed through cell-cell interactions to the nonexpressing region; and (3) the fate of these cells may depend on the low level of $t s g$ expression that occurs before blastoderm formation. However, lack of cell autonomy in gynandromorphs (Zusman and Wieschaus 1985), coupled with the structural features of a secreted protein, is consistent with a signaling role for TSG.

The fact that TSG exhibits some limited similarity with members of the CTGF gene family is notable when one compares the biological settings within which these molecules act. CTGF was identified in human umbilical vein endothelial cells (Bradham et al. 1991). It functions both as a cysteine-rich mitogen and as a powerful chemoattractant. The cytoskeletal rearrangements induced by CTGF during chemoattraction are similar to the cytoskeletal rearrangements that take place in amnioserosa cells in the presence of TSG function. Furthermore, CTGF and its relative CYR61 are present at sites of bone formation both in wound chambers and during development of limbs (G. Grotendorst and Fava, pers. comm.). Thus in mammals, BMP-1, BMP-2/4, CTGF, and CYR6 1 are all active in cells as they commit to bone 

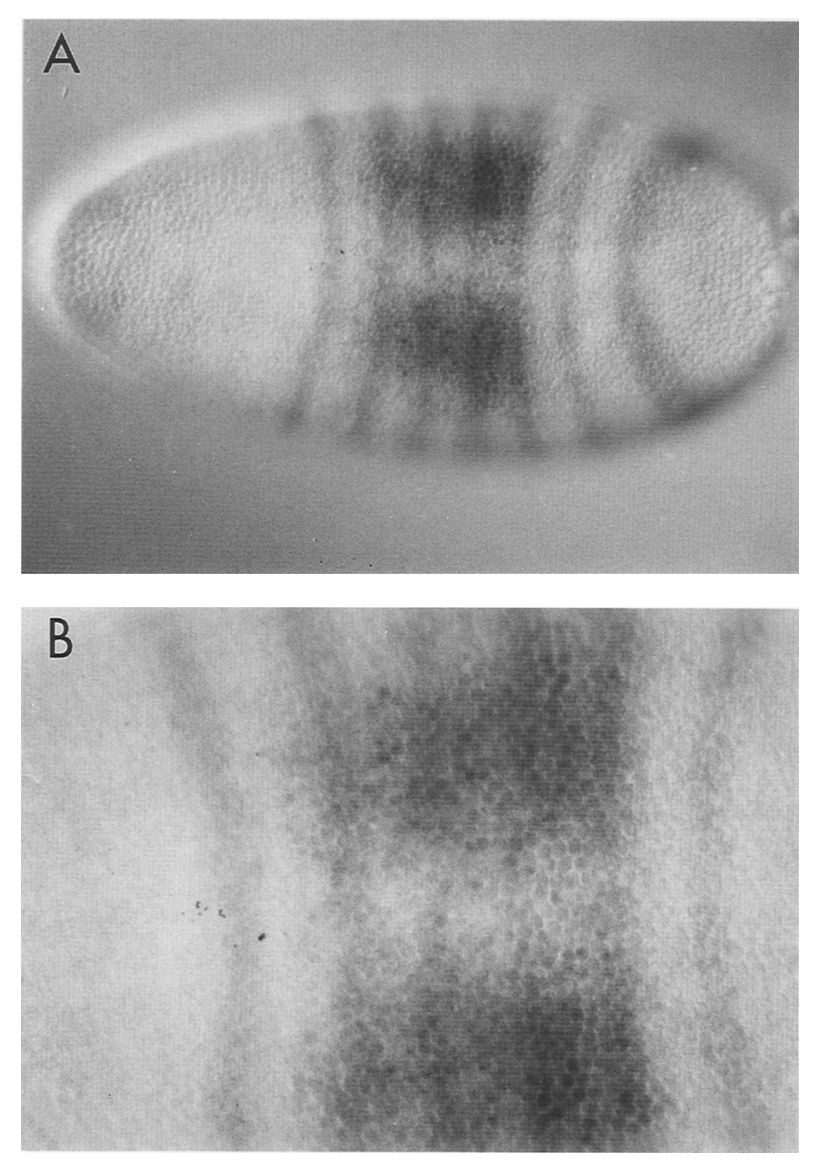

Figure 7. Localization of $t s g$ expression relative to $f t z$. Embryos were hybridized with both a tsg and a diluted $f t z$ probe. Dorsal views with anterior to the left. The $f t z$ probe stains evennumbered parasegments beginning with parasegment $2(A)$. Limited tsg expression is seen in the posterior of parasegment 3 and extends to parasegment 9 . Note the sharp boundaries defining domains of $f t z$ expression vs. the diffuse boundaries of $t s g$ expressing domains. (B) A higher magnification photograph of the central portion of the embryo shown in $A$. Note the uniform staining of the $f t z$ probe. The $t s g$ staining is uniform in some cells and intensely concentrated apically in others. For comparative purposes, the complexity and dilutions of the two probes are described in Results.

deposition, whereas in Drosophila, the closest relatives of each of these different classes of genes are active in cell fate specification in the early embryo (i.e., TLD, DPP, SCW, TSG). The coincidence of finding a similar constellation of molecules associated with cell commitment in mammals and in Drosophila is notable.

\section{Models of TSG action}

Models of TSG action are based on different assumptions about the spatial requirements of TSG activity and different assumptions about the temporal and/or mechanistic requirements of TSG action relative to DPP. Spatially, TSG activity may be required over the entire dorsal half of the embryo (Fig. 10, model A) or the requirement for TSG activity may be restricted to the dorsal midline (Fig. 10, models B1-B3). Temporally or mechanistically TSG may act upstream, downstream, or in parallel with DPP. The considerations discussed below lead us to favor the restricted combinatorial model (Fig. 10, model B3) over the others.

It has been suggested that the zygotic ventralizing genes function to establish or modulate a DPP gradient over the dorsal half of the embryo (Ferguson and Anderson 1992b). By this model, mutations in modulating genes will lower the DPP gradient (Fig. 10, model A), thus narrowing the dorsal domain and causing loss of cell fates at the apex of the gradient. The behavior of $t l d$ and scw mutations is consistent with a role in establishing a putative DPP activity gradient (Shimell et al. 1991; Arora and Nüsslein-Volhard 1992; Ferguson and Anderson 1992b). Weak alleles of tld and scw lead to loss of dorsal midline fates, which may require the highest DPP activity, whereas stronger alleles lead to loss of dorsal ectoderm cell fates as well. As DPP activity is reduced, dorsal fates are lost and ventral domains expand (Arora and Nüsslein-Volhard 1992). Mutants in the DPP gradient-modulating genes also cause the expression of the dorsal ectoderm-specific gene P62 to narrow and lead to a dorsal shift of mitotic domains (Arora and NüssleinVolhard 1992). By the three criteria examined, the effect of $t s g$ mutations is inconsistent with a role in the establishment or maintenance of a global DPP gradient, as only cells along the dorsal midline are affected by tsg mutations. Specifically, the only cuticular structures lost derive from the dorsal midline, whereas structures from the more lateral dorsal ectoderm are unaffected; the P62 enhancer trap that is normally expressed only in the dorsal ectoderm is now expressed in an extended domain that includes cells of the dorsal midline and the dorsal ectoderm; finally, dorsolateral mitotic domains seen at gastrulation now extend across the dorsal midline and do not shift dorsally. Thus, $t s g$ function is required only in the dorsal midline, and in its absence, dorsal midline cells adopt dorsal ectoderm identities. Model A is eliminated.

In the midline, TSG may act temporally or mechanistically upstream, downstream, or in parallel with DPP (Fig. 10, models B1-B3). For example, TSG may act upstream of DPP by creating a peak of DPP activity at the dorsal midline (Fig. 10, model B1). Several considerations suggest that this is unlikely. Mutations in tsg are not suppressed by a fourfold increase in $d p p$ gene dose, whereas this increase is sufficient to suppress mutations in srw, as well as tld, and scw (Ferguson and Anderson 1992b). If TSG serves to create a peak of DPP activity, increases in DPP levels might be expected to compensate for the loss of TSG (e.g., similar to the suppression of $s r w)$. A putative interaction of TSG with DPP could be either direct or indirect; however, TSG does not exhibit any structural features that might suggest a direct physical interaction with DPP (e.g., membrane-anchoring sequences, homology to TGF- $\beta$-binding proteins, or homology to catalytic domains that might be involved in activation or modulation of DPP). If TSG acts indirectly 

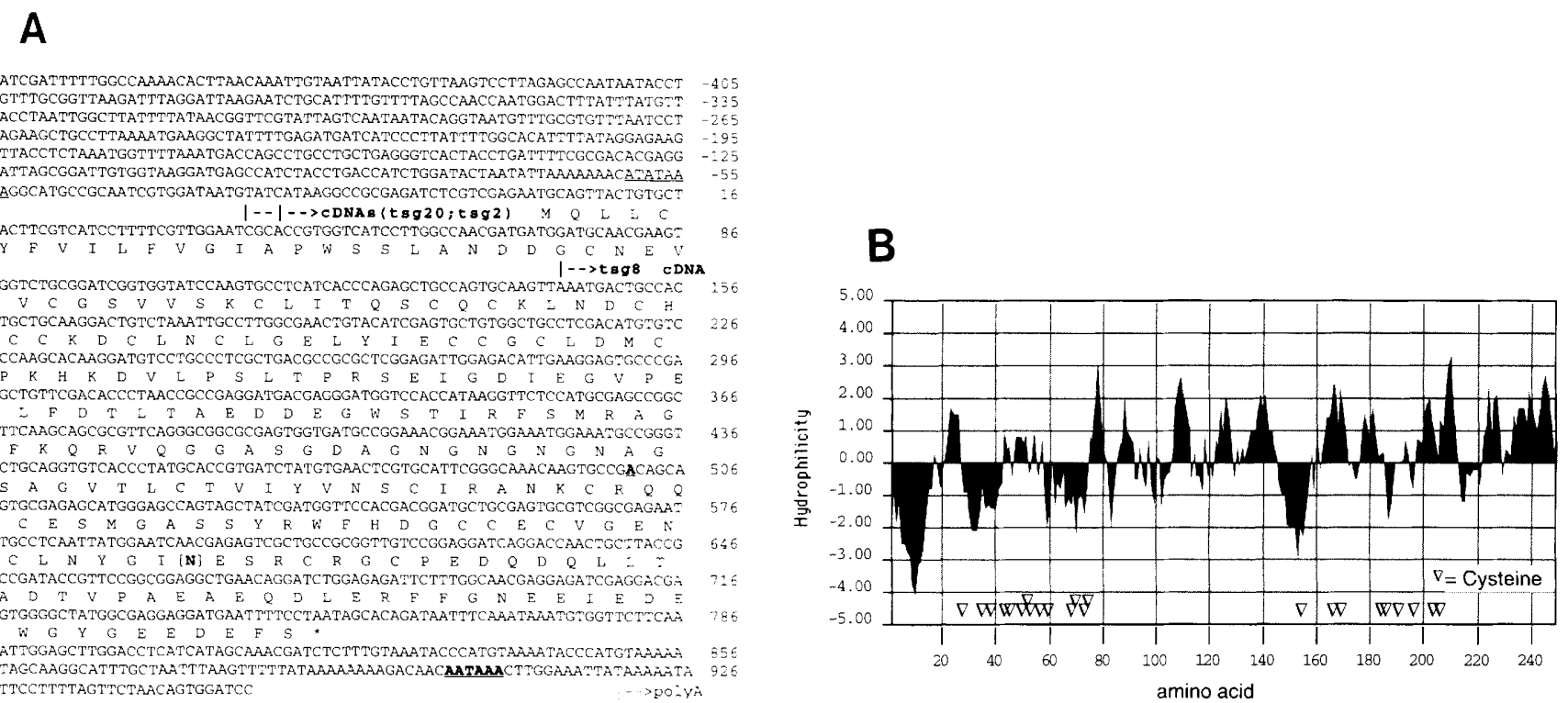

Figure 8. Sequence and structure of the $t s g$ gene. $(A)$ Sequence of the tsg gene. This is a composite of genomic and cDNA sequence. Three cDNAs were sequenced completely, and the $5^{\prime}$ ends are indicated by arrows. An appropriately placed TATA box in the flanking genomic sequence is underlined at $-60 \mathrm{bp}$, the one potential $\mathrm{N}$-glycosylation site is bracketed at $595 \mathrm{bp}$, and a poly(A) addition sequence at $901 \mathrm{bp}$ is underlined. The tsg 2 clone was judged to be full length because it contained the entire ORF, was the same size as the mature mRNA, contained a 42 -nucleotide poly $(\mathrm{A})$ tail, and began at base -26 nucleotides, within 2 bases of the start of clone $t s g 20$ at -29 nucleotides. Clone $t s g 20$ terminated early at nucleotide 495 . Clone $t s g 8$ was truncated, beginning at nucleotide 74 and terminating at nucleotide 860 . The sequences of genomic and cDNA clones were identical except for an A in the cDNA (A at 501) that is replaced by $\mathrm{G}$ in the genomic sequence. (This sequence has been submitted to GenBank under accession no. U09808). (B) Hydropathy plot of TSG. Hydropathy was calculated using a window size of 5 (Kyte and Doolittle 1982). The location of cysteine residues is indicated by arrowheads $(\nabla)$ to illustrate their nonuniform distribution. The amino terminus (left) shows the hydrophobic signature characteristic of a secretory signal sequence. No other potential membrane-spanning domain is seen.

on DPP, excess DPP should be even more likely to be epistatic to loss of TSG function. Thus, model Bl is unlikely.

Alternatively, TSG may act downstream of DPP to set midline cell fate (Fig. 10, model B2). If downstream of DPP, extra doses of $d p p$ should fail to suppress tsg mutations as they do (Ferguson and Anderson 1992b). DPP might regulate $t s g$ by regulating expression or by posttranslationally regulating activation of TSG. We find that $t s g$ expression is present and nearly unaltered in $d p p$ mutant embryos (C.D. Webb and J.L. Marsh, unpubl.) as compared with wild-type embryos; thus, if TSG acts downstream of DPP, it must be through post-translational modification of the TSG protein directly or indirectly. Presently, there are no known genetic interactions between tsg and $d p p$ or structural features of DPP that might suggest such a role. Thus, model B2, although not rigorously eliminated, appears less parsimonious than model B3.

Finally, midline cell fate may be set by the combined input of TSG acting as a second growth factor in concert with DPP (Fig. 10, model B3). In this model, DPP signal alone would specify dorsal ectoderm cell fates, whereas cells receiving both DPP and TSG input would adopt dorsal midline fates. This readily accounts for the fact that lateral dorsal ectoderm fates are unchanged in tsg mutants, whereas midline cells adopt lateral fates /they receive only DPP input). Recall the staining of P62 across the whole dorsal half of the embryo; the mitotic domains whose lateral boundaries did not retreat but whose dorsal boundaries extended across the midline and the presence of lateral cuticle elements in tsg mutant embryos. This mechanism is also supported by the structural data

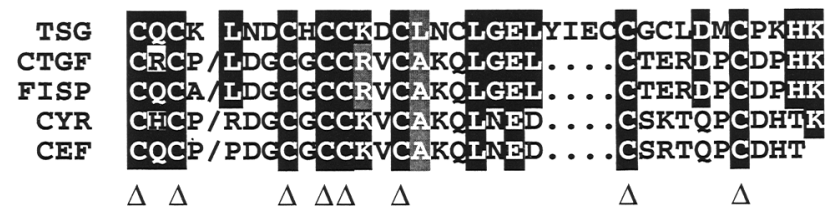

Figure 9. TSG shares a motif with a family of vertebrate proteins. A portion of the amino-terminal region of TSG is aligned with its four closest relatives, human CTGF, the murine homolog FISP-12, CYR61, and CEF-10, which were identified by the BLAST algorithm (Altschul et al. 1990). The slash (/) indicates the insertion of 15 amino acids in the mammalian proteins. Of the 32 aligned amino acids $(59 \%), 19$ are identical or conserved. Identical amino acids are indicated by black shading and conservative changes by a gray background. Conserved cysteine residues are indicated with arrowheads $\nabla$. All proteins are preceded by a hydrophobic signal sequence (not shown). The proteins were aligned using the PILEUP algorithm in the UWGCG program package (gap weight $=2.0$; gap length $=0$ ) with adjustments. The GenBank files used were MUSFISP12A, CHKCEF, MUSCYR61A, HUMCONGRO_1 (CTGF). The amino acids shown are TSG 44-79, CTGF 29-78, FISP 28-78, CYR 26-74, and CEF 26-74. 


\section{A. TSG activity required in all dorsal cells}
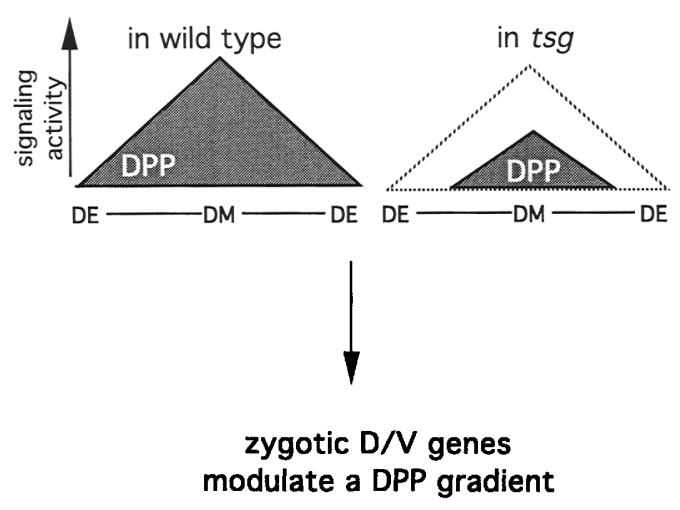

TLD SCW SRW TSG

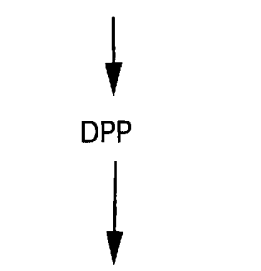

All dorsal

postional values
B. TSG required only in dorsal midline cells

Figure 10. Models of TSG action. Four possible models of TSG action are summarized. (Model $A$ ) TSG acts across the entire dorsal half of the embryo, perhaps by modulating a DPP gradient. Dorsal patterning would result from differential responses to a gradient of DPP activity with other zygotic ventralizing genes serving to establish or maintain that gradient. Mutations in effector genes would be active over the entire dorsal $40 \%$ of the embryo and would cause shifts of the fate map so that dorsal and dorsal lateral fates shifted toward the dorsal midline or disappeared. (Model $B$ ) TSG activity is restricted to the dorsal midline, where it acts upstream (model B1), downstream (model B2), or in parallel with (model B3) DPP. If upstream (model B1), TSG may serve to maintain a peak of DPP activity at the midline. A gradient of DPP activity could still provide the primary patterning signal but TSG would be required only in the dorsal midline to maintain a localized peak of DPP activity. In the absence of TSG function, the peak would dissipate leading to loss of midline derivatives, but lateral cells would continue to experience near normal levels of DPP, and thus patterning in the dorsal ectoderm (see Fig. 1D) would remain essentially unchanged. (Model B2) TSG could act downstream of DPP to specify midline cell fate. This implies that DPP is required to turn tsg on or is required to activate the TSG protein that then properly signals dorsal midline cell fate. (Model B3) A combinatorial system of cell signaling could drive dorsal patterning. In the combinatorial model, DPP activity would be required in the dorsal $45-50 \%$ of the embryo, but TSG would function as an independent signaling factor that would affect only the dorsal most $10 \%$. In the combinatorial view, DPP + TSG = dorsal midline (DM), whereas DPP alone $=$ dorsal ectoderm (DE). In the absence of TSG function, midline cells would see only DPP and become dorsal ectoderm but dorsal ectoderm would remain unchanged. For reasons described in the text, the combinatorial model most readily accounts for the experimental observations.

suggesting that TSG is a secreted molecule related to a known mammalian growth factor (CTGF). This possibility accounts for the failure of extra doses of $d p p$ to suppress tsg mutations (Ferguson and Anderson 1992b), as it did in model B2 above. The lack of concordance between the site of TSG synthesis and the location of cells requiring TSG activity suggests that only presumptive midline cells are competent to respond to the proposed dual input of TSG and DPP, thus, implying an as yet undiscovered midline gene required for cells to respond to this signal. We propose the working hypothesis that dorsal midline fate is specified by the combined input of a TSG and DPP signal and that response to this signal is con- trolled by selective competence to respond to widely available signals (DPP and TSG) rather than by restricted availability of the signal as, for example, with wingless (Noordermeer et al. 1992; Theisen et al. 1994).

Cell fate along the A/P axis of the Drosophila embryo takes place before cellularization and is specified by the graded distribution of transcription factors in the syncytial blastoderm. In most other embryos and in the $\mathrm{D} / \mathrm{V}$ axis of Drosophila embryos, cell fate specification requires a mechanism that operates in a field of cells. Two possible mechanisms to accomplish this are a differential responsiveness to a graded diffusible morphogen (e.g., a gradient of DPP) or a combinatorial input of mul- 
tiple signaling molecules (e.g., DPP $+\mathrm{TSG}=$ dorsal midline; DPP only $=$ dorsal ectoderm). For example, in animal cap explants from Xenopus embryos, different concentrations of activin induce at least three different tissue types (Ariizumi et al. 1991) suggesting a graded diffusible morphogen model. Alternatively, it has been found that activin and FGF can act together to specify cell fates in animal cap explants from Xenopus embryos (Green et al. 1992), as activin and fibroblast growth factor (FGF) together at low concentrations result in levels of muscle induction that neither signaling molecule alone could produce at that low concentration. Similarly, a mammalian cell line competent to differentiate into muscle, fat, and cartilage cells responds in a dosedependent manner to BMP-2, whereas addition of other growth factors together with BMP-2 alter the frequency of the differentiated colony formation (Wang et al. 1993). Although a differential response to a graded signaling molecule (such as DPP) can account for some observations (Ferguson and Anderson 1992a), the models discussed above lead us to favor the view that TSG may function as an independent peptide growth factor acting in parallel with DPP, thus, implying that multiple diffusible growth factors may be a general theme in early embryonic patterning in both vertebrates and invertebrates.

\section{Materials and methods}

\section{Histology and stocks}

The literature contains confusing allele designations for $t s g \mathrm{mu}$ tants. Some investigators refer to $t s g^{\mathrm{XB} 86}$ and $t s g^{\mathrm{YN} 97}$ (Ray et al. 1991; Ferguson and Anderson 1992b|, whereas Zusman and Wieschaus (1985) refer to $t s g^{B 8}$ as a null and the Drosophila stock center refers to the second allele as $t s g^{\mathrm{N} 9}$. We confirmed that both of the $t s g$ alleles used here, $t s g^{\mathrm{N} 9}$ and $t s g^{\mathrm{B} 8}$, are null alleles by comparing embryos homozygous for the mutations to embryos hemizygous for $D f(1) R C 29$. All of the structures affected are described in the first section of Results. To examine cuticle preparations, staged embryos from $t s g$ heterozygotes and wild type (Ore-R) were collected, dechorionated in $50 \%$ bleach, treated in a $1: 1$ mixture of $10 \%$ formaldehyde-PBS and heptane for $5 \mathrm{~min}$ followed by removal of the PBS layer and addition of an equal volume of methanol followed by vigorous shaking to remove the vitelline membrane. After two 5-min rinses in PBS, embryos were placed under coverslips in 1:1 Hoyer's/lactic acid (Wieschaus and Nüsslein-Volhard 1986). After a few hours at $65^{\circ} \mathrm{C}$, the tissue was cleared and the embryos were viewed by dark-field and phase microscopy using a Nikon optiphot microscope.

To stain the dorsal ectoderm-specific enhancer trap, 4- to 6-hr embryos were collected from $t 1 d^{68}[$ P62]/TM3 (a tld null allele with the enhancer trap P-element, P62, on the tld chromosome), Ore-R [P62]/[P62] (third chromosome), and from the cross, Ore-R [P62]/[P62] males with $w$ tsg ${ }^{\mathrm{N} 9} / \mathrm{FM} 7 \mathrm{c}$ and $y t s g^{\mathrm{B} 8} / \mathrm{FM} 7 \mathrm{c}$ females. Embryos were dechorionated and the vitelline membranes removed as above, blocked in a solution of PBS, $0.1 \%$ Triton, 1\% BSA (PBT-BSA) three times for $30 \mathrm{~min}$ each and incubated overnight at $4^{\circ} \mathrm{C}$ with a $1: 1000$ mouse anti- $\beta$-galactosidase antibody (Promega) in PBT-BSA. Embryos were incubated in a 1:1000 anti-mouse horseradish peroxidase (HRP) secondary (Zymed), $4 \mathrm{hr}$ at room temperature or overnight at $4^{\circ} \mathrm{C}$, followed by three 20-min washes in PBT and stained for $\sim 1 \mathrm{~min}$ in $1 \mathrm{ml}$ of citric acid buffer $(\mathrm{pH} 6.3)(0.1 \mathrm{M}$ citric acid, $0.05 \mathrm{M}$ $\mathrm{NH}_{4} \mathrm{O}$ acetate) with $0.5 \mathrm{mg}$ of diaminobenzidine (DAB) and $2 \mu \mathrm{l}$ of $30 \% \mathrm{H}_{2} \mathrm{O}_{2}$. Staining was stopped by rinsing embryos in PBT. Embryos were mounted on slides in $70 \%$ glycerol and 30\% PBS and photographed using Nomarski optics.

\section{Molecular procedures}

Total RNA was isolated from staged animals essentially as described by LeMeur et al. (1981) and adapted for small amounts of Drosophila tissue by J. Rawls and G. Richards (pers. comm.). The RNA was separated using denaturing formaldehyde-agarose gels and transferred to nylon membranes (Fourney et al. 1988 | ${ }^{32} \mathrm{P}$-Labeled single-stranded RNA probes were transcribed with $\mathrm{T} 7$ or $\mathrm{T} 3$ polymerase from cDNAs subcloned into the Bluescript vector (Stratagene).

cDNA clones were obtained from 0- to 4-hr embryo libraries (Poole et al. 1985) (tsg8) and (Brown and Kafatos 1988) (tsg2; tsg20| using genomic subclones characterized previously as hybridizing to tsg mRNA (Goralski 1985). DNA was sequenced from double-stranded plasmid templates using the dideoxy chain termination method with modifications described in the Sequenase kit of U.S. Biochemical. Overlapping subclones spanning the entire cDNA and genomic sequence encoding the tsg gene were isolated using conveniently spaced restriction sites and one oligonucleotide primer. Both strands were sequenced and all cloning sites were crossed. One polymorphism was detected between the sequence from the genomic library (Maniatis et al. 1978) and the sequence from the cDNA library (Poole et al. 1985). Nucleotide +501 was $G$ in the genomic sequence and $\mathrm{A}$ in the cDNA sequence. This nucleotide occupies the third position in a codon and both sequences code for arginine. Otherwise, no differences were observed between the genomic and cDNA sequences. Routine DNA manipulations were performed according to standard methods (Sambrook et al. 1989).

\section{In situ hybridizations}

RNA probes were labeled according to the protocol accompanying the DIG RNA Labeling Mixture (Boehringer Mannheim). Unincorporated ribonucleotides were removed by $\mathrm{P}-60$ column chromatography equilibrated with $1 \times$ TEN buffer $[0.1 \mathrm{M} \mathrm{NaCl}$, $10 \mathrm{~mm}$ Tris-HCl, $1 \mathrm{~mm}$ EDTA (pH 8.0)]. Approximately $1 \mu \mathrm{g}$ of hydrolyzed probe was used for each hybridization in a final volume of $50 \mu \mathrm{l}$.

Embryos were treated for hybridization as described (Tautz and Pfeifle 1989), with the following modifications: The initial fixation buffer contained $10 \%$ formaldehyde and 50 mM EGTA, and the embryos were transferred directly to ethanol after fixation. The embryos were digested with $5 \mu \mathrm{g} / \mathrm{ml}$ of proteinase $\mathrm{K}$ and prehybridized at $55^{\circ} \mathrm{C}$ (determined empirically to be optimal for our RNA probes). Probe was added to the embryos at a final concentration of $\sim 10 \mathrm{ng} / \mu \mathrm{l}$ in a $50-\mu \mathrm{l}$ volume and hybridized for 3 nights at $55^{\circ} \mathrm{C}$. Posthybridization washes continued for 3 days at $55^{\circ} \mathrm{C}$ with at least six changes of hybridization buffer. We found that shorter wash times resulted in background staining appearing sooner (e.g., $\sim 45 \mathrm{~min}$ ), which is not a problem with transcripts such as $\mathrm{ftz}$ / which signal appears in $\leqslant 1$ min) but completely prevented visualization of $t s g$, which is approximately $\leqslant 1 \%$ as abundant and required $\sim 1-3 \mathrm{hr}$ to develop. After washing, embryos were prepared for antibody and staining as described and mounted in $70 \%$ glycerol in $1 \times \mathrm{PBT}$ for photography using a Nikon microscope with Nomarski optics, a Nikon camera, and Kodak HCl00 Ektachrome daylight film. The $1.7-\mathrm{kb} \mathrm{ftz}$ cDNA (G20) was a kind gift of Dr. T. 
Kaufman's laboratory (Laughon and Scott 1984) The tsg probe was 563 nucleotides of the 5 ' portion of the gene chosen to avoid the GN repeat region within the gene and a poly $(G)$ cloning leader in the cDNA that caused background problems.

\section{Examination of mitotic domains}

Embryos were collected from OreR wild type, y $\mathrm{tsg}^{\mathrm{B}} / F M 7 \mathrm{c}$ and $w$ tsg ${ }^{N 9} / F M 7 c$ stocks and treated as described by (Foe 1989). Briefly, embryos were treated with taxol to stabilize microtubules, incubated with an anti- $\beta$-tubulin monoclonal antibody (Amersham N357) at a 1:500 dilution and stained with FITClabeled goat anti-mouse antibody. Embryos were mounted in glycerol-gallate [ $5 \% \mathrm{~N}$-propyl gallate, $50 \%$ glycerol, and $100 \mathrm{~mm}$ Tris $[\mathrm{pH} 91]$ and viewed in a BioRad Laser Scanning Confocal Microscope Model MRC 600 attached to a Nikon Optiphot microscope using a $25 \times$ oil immersion Zeiss lens. Pictures shown here are " $z$-series" reconstructions of the optical sections.

\section{Acknowledgments}

We are indebted to T. Goralski and A.P. Mahowald for sharing information and clones before publication and to W. Gelbart, V. Twombly, G. Grotendorst, and K. Arora for sharing their unpublished results. Special acknowledgment is due to M. O'Connor and K. Arora for advice and assistance, to D. Woods for help with the Northern analysis, to J. Purcell for sequencing of $t s g$, and to J. Maloney for early work with the in situ hybridization studies as part of an undergraduate research project. Part of this material was submitted by C.D.W. in partial fulfillment of the undergraduate Excellence in Research requirements at University of California, Irvine (UCI). We gratefully acknowledge the support of the National Science Foundation (NSF) grant DC8615701 to K.D.K./J.L.M. and DCB8904047 to K.D.K., and National Institutes of Health grant GM28972 to J.L.M. and the support of NIH Training Grant HD07029 for E.D.M. C.D.W. was partially supported by an REU supplement to NSF grant DCB8916666 (J.L.M.), and an undergraduate research grant from the Committee for Instructional Development (UCI). We gratefully acknowledge the computational support of GenBank and the UCI office of academic computing, and the resources of the National Drosophila Stock Center in Bloomington, IN.

The publication costs of this article were defrayed in part by payment of page charges. This article must therefore be hereby marked "advertisement" in accordance with 18 USC section 1734 solely to indicate this fact.

\section{References}

Altschul, S.F., W. Gish, W. Miller, E.W. Myers, and D.J. Lipman. 1990. Basic local alignment search tool. I. Mol. Biol. 215: 403-410.

Ariizumi, T., N. Moriya, H. Uchiyama, and M. Asashima. 1991. Concentration-dependent inducing activity of activin A. Wilhelm Roux's Arch. Dev. Biol. 200: 230-233.

Arora, K. and C. Nüsslein-Volhard. 1992. Altered mitotic domains reveal fate map changes in Drosophila embryos mutant for zygotic dorsoventral patterning genes. Development 114: 1003-1024.

Baxter, R.C. 1988. The insulin-like growth factors and their binding proteins. Comp. Biochem. Physiol. 91: 229-235.

Bilofsky, H.S. and C. Burks. 1988. The GenBank (R) Genetic Sequence Data Bank. Nucleic Acids Res. 16: 1861-1864.

Bradham, D.M., A. Igarashi, R.L. Potter, and G.R. Grotendorst. 1991. Connective tissue growth factor: A cysteine-rich mi- togen secreted by human vascular endothelial cells is related to the SRC-induced immediate early gene product CEF-10. I. Cell Biol. 114: 1285-1294.

Brown, N.H. and F.C. Kafatos. 1988. Functional cDNA libraries from Drosophila embryos. J. Mol. Biol. 203: 425-437.

Campos-Ortega, J.A. and V. Hartenstein. 1985. The embryonic development of Drosophila melanogaster. Springer-Verlag, Berlin/New York.

Celeste, A.J., J.A. Iannazzi, R.C. Taylor, R.M. Hewick, V. Rosen, E.A. Wang, and J.M. Wozney. 1990. Identification of transforming growth factor beta family members present in boneinductive protein purified from bovine bone. Proc. Natl. Acad. Sci. 87: 9843-9847.

Doyle, H.J., K. Harding, T. Hoey, and M. Levine. 1986. Transcripts encoded by a homoeo box gene are restricted to dorsal tissues of Drosophila embryos. Nature 323: 76-79.

Doyle, H.J., R. Kraut, and M. Levine. 1989. Spatial regulation of zerknüllt: A dorsal-ventral patterning gene in Drosophila. Genes \& Dev. 3: 1518-1533.

Ferguson, E.L. and K.V. Anderson. 1991. Dorsal-ventral pattern formation in the Drosophila embryo: The role of zygotically active genes. Curr. Top. Dev. Biol. 25: 17-43.

- 1992a. Decapentaplegic acts as a morphogen to organize dorsal-ventral pattern in the Drosophila embryo. Cell 71: 451-461.

1992b. Localized, enhancement and repression of the activity of the TGF- $\beta$ familiy member, decapentaplegic: is necessary for dorsal-ventral pattern formation in the Drosophila embryo. Development 114: 583-597.

Foe, V.E. 1989. Mitotic domains reveal early commitment of cells in Drosophila embryos. Development 107: 1-22.

Fourney, R.M., J. Miyakoshi, R.S. Day III, and M.C. Paterson. 1988. Northern blotting: Efficient RNA staining and transfer. Focus 10: 5-6.

Goralski, T. 1985. "A molecular analysis of the female sterile locus gastrulation defective $(g d)$ of Drosophila melanogaster." Ph.D. thesis, Indiana University, Bloomington, IN.

Green, J.B., H.V. New, and J.C. Smith. 1992. Responses of embryonic Xenopus cells to activin and FGF are separated by multiple dose thresholds and correspond to distinct axes of the mesoderm. Cell 71: 731-739.

Hafen, E., A. Kuroiwa, and W.J. Gehring. 1984. Spatial distribution of transcripts from the segmentation gene fushi tarazu during drosophila embryonic development. Cell 37: 833841.

Hultmark, D., R. Klemenz, and W.J. Gehring. 1986. Translational and transcriptional control elements in the untranslated leader sequence of the heat-shock gene hsp22. Cell 24: 251-260.

Irish, V.F. and W.M. Gelbart. 1987. The decapentaplegic gene is required for dorsal-ventral patterning of the Drosophila embryo. Genes \& Dev. 1: 868-879.

Jürgens, G. 1987. Segmental organisation of the tail region in the embryo of Drosophila melanogaster. A blastoderm fate map of the cuticle structures of the larval tail region. Wilhelm Roux's Arch. Dev. Biol. 196: 141-157.

Jürgens, G., E. Wieschaus, C. Nüsslein-Volhard, and H. Kluding. 1984. Mutations affecting the pattern of the larval cuticle in Drosophila melanogaster. II. Zygotic loci on the third chromosome. Wilhelm Roux's Arch. Dev. Biol. 193: 283-295.

Jürgens, G., R. Lehmann, M. Schardin, and C. Nüsslein-Volhard. 1986. Segmental organisation of the head in the embryo of Drosophila melanogaster. A blastoderm fate map of the cuticle structures of the larval head. Wilhelm Roux's Arch. Dev. Biol. 195: 359-377.

Kyte, J. and R.F. Doolittle. 1982. A simple method for displaying 
the hydropathic character of a protein. J. Mol. Biol 157: 105132.

Laughon, A. and M. Scott. 1984. Sequence of a Drosophila segmentation gene: Protein structure homology with DNAbinding proteins. Nature 310: 25-31.

LeMeur, M., N. Glanville, J.L. Mandel, P. Gerlinger, R. Palmiter, and P. Chambon. 1981. The ovalbumin gene family: Hormonal control of $X$ and $Y$ gene transcription and mRNA accumulation. Cell 23: 561-571.

Maniatis, T., R.C. Hardison, E. Lacy, J. Lauer, C. O'Connell, D. Quon, D.K. Sim, and A. Efstratiadis. 1978. The isolation of structural genes from libraries of eukaryotic DNA. Cell 15: 687-699.

Noordermeer, J., P. Johnston, F. Rijsewijk, R. Nusse, and P.A. Lawrence. 1992. The consequences of ubiquitous expression of the wingless gene in the Drosophila embryo. Development 116: 711-719.

Nüsslein-Volhard, C., E. Wieschaus, and H. Kluding. 1984. Mutations affecting the pattern of the larval cuticle in Drosophila melanogaster. I. Zygotic loci on the second chromosome. Wilhelm Roux's Arch. Dev. Biol. 193: 267-282.

O'Brien, T.P., G.P. Yang, L. Sanders, and L.F. Lau. 1990. Expression of cyr61: A growth factor-inducible immediate-early gene. Mol. Cell. Biol. 10: 3569-3977.

Padgett, R.W., J.M. Wozney, and W.M. Gelbart. 1993. Human BMP sequences can confer normal dorsal-ventral patterning in the Drosophila embryo. Proc. Natl. Acad. Sci. 90: 29052909.

Poole, S.J., L.M. Kauvar, B. Drees, and T. Kornberg. 1985. The engrailed locus of Drosophila: Structural analysis of an embryonic transcript. Cell 40: $37-43$.

Ray, R.P., K. Arora, C. Nüsslein-Volhard, and W.M. Gelbart. 1991. The control of cell fate along the dorsal-ventral axis of the Drosophila embryo. Development 113: 35-54.

Rushlow, C. and K. Arora. 1990. Dorsal ventral polarity and pattern formation in the Drosophila embryo. Sem. Cell Biol. 1: $137-149$.

Ryseck, R.P., B.H. Macdonald, M.G. Mattei, and R. Bravo. 1991. Structure, mapping, and expression of fisp-12, a growth factor-inducible gene encoding a secreted cysteine-rich protein. Cell Growth Differ. 2: 225-233.

Sambrook, J., E.F. Fritsch, and T. Maniatis. 1989. Molecular cloning: A laboratory manual, 2nd ed. Cold Spring Harbor Laboratory Press, Cold Spring Harbor, New York.

Shimell, M.J., E.L. Ferguson, S.R. Childs, and M.B. O'Connor. 1991. The Drosophila dorsal-ventral patterning gene tolloid is related to human bone morphogenetic protein 1. Cell 67: 469-481.

Simmons, D.L., D.B. Levy, Y. Yannoni, and R.L. Erikson. 1989. Identification of a phorbol ester-repressible v-src-inducible gene. Proc. Natl. Acad. Sci. 86: 1178-1182.

St. Johnston, R.D. and W.M. Gelbart. 1987. Decapentaplegic transcripts are localized along the dorsal-ventral axis of the Drosophila embryo. EMBO I. 6: 2785-2791.

St. Johnston, D. and C. Nüsslein-Volhard. 1992. The origin of pattern and polarity in the Drosophila embryo. Cell 68: 201219.

Tautz, D. and C. Pfeifle. 1989. A non-radioactive in situ hybridization method for the localization of specific RNAs in Drosophila embryos reveals translational control of the segmentation gene hunchback. Chromosoma 98: 81-85.

Theisen, H., J. Purcell, M. Bennett, D. Kansagara, A. Syed, and J. Marsh. 1994. dishevelled is required during wingless signaling to establish both cell polarity and cell identity. Development 120: 347-360.

von Heinje, G. 1986. A new method for predicting signal se- quence cleavage sites. Nucleic Acids Res. 14: 4683-4690.

Wakimoto, B.T., F.R. Turner, and T.C. Kaufman. 1984. Defects in embryogenesis in mutants associated with the Antennapedia gene complex of Drosophila melanogaster. Dev. Biol. 102: 147-172.

Wang, E.A., V. Rosen, P. Cordes, R.M. Hewick, M.J. Kriz, D.P. Luxenberg, B.S. Sibley, and J.M. Wozney. 1988. Purification and characterization of other distinct bone-inducing factors. Proc. Natl. Acad. Sci. 85: 9484-9488.

Wang, E.A., D.I. Israel, S. Kelly, and D.P. Luxenberg. 1993. Bone morphogenetic protein-2 causes commitment and differentiation in C3H10Tl/2 and 3T3 cells. Growth Factors 9: 5771.

Wharton, K.A., R.P. Ray, and W.M. Gelbart. 1993. An activity gradient of decapentaplegic is necessary for the specification of dorsal pattern elements in the Drosophila embryo. Development 117: 807-822.

Wieschaus, E. and C. Nüsslein-Volhard. 1986. Looking at embryos. In Drosophila, a practical approach, (ed. D.B. Roberts), pp. 199-228, IRL Press, Oxford, UK.

Wieschaus, E., C. Nüsslein-Volhard, and G. Jürgens. 1984. Mutations affecting the pattern of the larval cuticle in Drosophila melanogaster. III. Zygotic loci on the X-chromosome and fourth chromosome. Wilhelm Roux's Arch. Dev. Biol. 193: $296-307$.

Wozney, J.M., V. Rosen, A.J. Celeste, L.M. Mitsock, M.J. Whitters, R.W. Kriz, R.M. Hewick, and E.A. Wang. 1988. Novel regulators of bone formation: Molecular clones and activities. Science 242: 1528-1534.

Zusman, S. and E. Wieschaus. 1985. Requirements for zygotic gene activity during gastrulation in Drosophila melanogaster. Dev. Biol. 111: 359-371. 


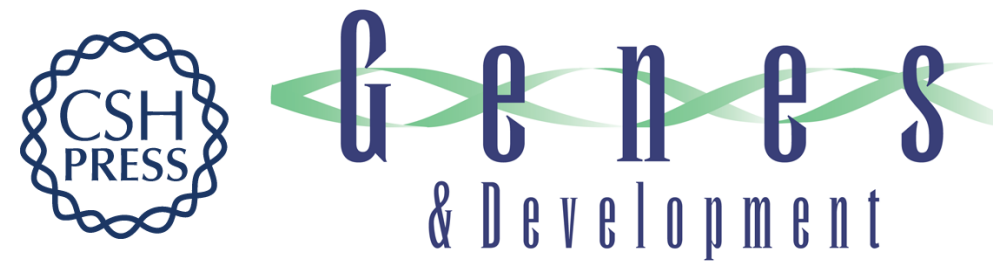

\section{Dorsal midline fate in Drosophila embryos requires twisted gastrulation, a gene encoding a secreted protein related to human connective tissue growth factor.}

E D Mason, K D Konrad, C D Webb, et al.

Genes Dev. 1994, 8:

Access the most recent version at doi:10.1101/gad.8.13.1489

References This article cites 48 articles, 17 of which can be accessed free at:

http://genesdev.cshlp.org/content/8/13/1489.full.html\#ref-list-1

License

Email Alerting Receive free email alerts when new articles cite this article - sign up in the box at the top Service right corner of the article or click here.

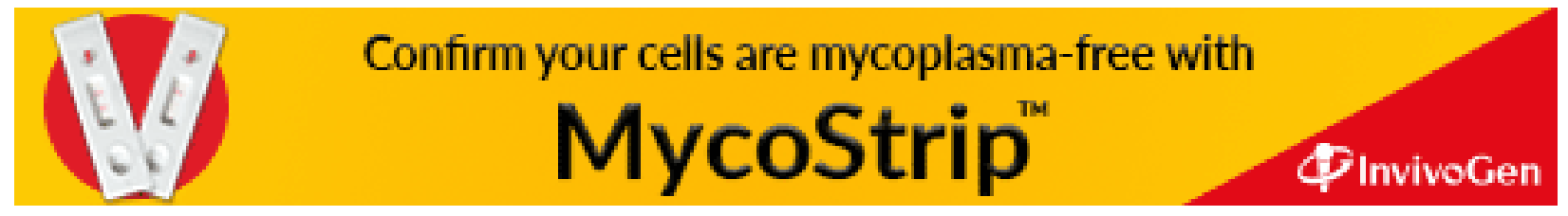

